\title{
Generation of murine macrophage-derived cell lines expressing porcine CD163 that support porcine reproductive and respiratory syndrome virus infection
}

Liangliang $\mathrm{Li}^{1,2+}$, Chunyan $\mathrm{Wu}^{1,2 \dagger}$, Gaopeng Hou ${ }^{1,2}$, Biyun Xue ${ }^{1,2}$, Sha Xie ${ }^{1,2}$, Qin Zhao ${ }^{1,2}$, Yuchen Nan ${ }^{1,2}$, Gaiping Zhang ${ }^{3}$ and En-Min Zhou ${ }^{1,2^{*}}$

\begin{abstract}
Background: Porcine reproductive and respiratory syndrome virus (PRRSV) exhibits a highly restricted tropism for cells of the monocyte-macrophage lineage, utilizing porcine CD163 (pCD163) as an indispensable cellular receptor for infection. Transfection the gene of pCD163 into several non-permissive cell lines followed by protein expression confers susceptibility to PRRSV. A lack of specialized porcine antibody tools for use with existing porcine-derived primary cells and cell lines has hampered studies of both PRRSV pathogenesis and virus triggering of immune response cascades. Therefore, we constructed PRRSV-susceptible murine alveolar macrophage-derived MH-S and peritoneal macrophage-like RAW264.7 cell lines by achieving pCD163 cell surface expression in these cells. We then evaluated PRRSV susceptibility and cytokine expression patterns induced upon PRRSV infection of these pCD163expressing cell lines.
\end{abstract}

Results: Growth of MH-S ${ }^{\mathrm{CD} 163}$ and RAW264.7 ${ }^{\mathrm{CD} 163}$ cells was indistinguishable from growth of un-transfected parental cell lines. Meanwhile, various stages of the PRRSV replication cycle, including viral particle attachment, internalization, disassembly and infection were confirmed in both pCD163-transfected cell lines. Analysis of PRRSV replication using immunofluorescence staining of virus and viral titration of cell lysates demonstrated that both $\mathrm{MH}$ $S^{\mathrm{CD} 163}$ and RAW264.7 $7^{\mathrm{CD} 163}$ cells supported replication of various genotype 2 PRRSV isolates. Moreover, PRRSV replication in MH-S ${ }^{\mathrm{CD} 163}$ cells was similar to that observed in porcine alveolar macrophages (PAMs) and was more efficient than in RAW264.7 $7^{\mathrm{CD} 163}$ cells. However, peak virus titers in MH-S ${ }^{\mathrm{CD} 163}$ cells were attained at $60 \mathrm{~h}$ postinfection (pi) versus $48 \mathrm{hpi}$ in PAMs. Analysis of cytokine expression showed that post-PRRSV infection, mRNA expression patterns of anti-inflammatory cytokines (IL-4 and IL-10) and pro-inflammatory cytokines (TNF- $a$ and IFN$\gamma$ ) in MH-S ${ }^{\text {CD163 }}$ cells were more similar to those observed in PAMs versus levels in RAW264.7 ${ }^{\mathrm{CD} 163}$ cells.

Conclusions: MH-S and RAW264.7 cells were not susceptible to PRRSV infection until transfection and subsequent expression of pCD163 were achieved in these cell lines. The PRRSV-susceptible MH-S ${ }^{\mathrm{CD} 163}$ cell line efficiently supported viral replication of various genotype 2 PRRSV isolates and exhibited similar cytokine expression patterns as observed in PAMs. In conclusion, this work describes the development of new tools to further understand PRRSV pathogenesis and immune response mechanisms to PRRSV infection.

Keywords: Murine macrophage-derived cells, Porcine CD163, PRRSV

\footnotetext{
* Correspondence: zhouem@nwsuaf.edu.cn

${ }^{\dagger}$ Equal contributors

'Department of Preventive Veterinary Medicine, College of Veterinary

Medicine, Northwest A\&F University, Yangling, Shaanxi, China

${ }^{2}$ Scientific Observing and Experimental Station of Veterinary Pharmacology

and Diagnostic Technology, Ministry of Agriculture, Yangling, Shaanxi, China

Full list of author information is available at the end of the article
} 


\section{Background}

Porcine reproductive and respiratory syndrome is a major swine infectious disease that causes severe economic losses for the global swine industry [1]. Its etiologic agent, porcine reproductive and respiratory syndrome virus (PRRSV), is an enveloped virus member of the family Arteriviridae, order Nidovirales, with a positive-stranded RNA genome [2,3]. There are two PRRSV genotypes; PRRSV-1 (genotype first isolated in Europe) and PRRSV-2 (genotype first isolated in North America) [4, 5]. These two genotypes share approximately $60 \%$ sequence identity but differ significantly serotype and virulence [6]. The PRRSV genome contains nine open reading frames (ORFs). ORFs $1 \mathrm{a}$ and $1 \mathrm{~b}$ comprise $80 \%$ of the viral genome and are predicted to encode the necessary enzymes for viral RNA replication. PRRSV ORFs 2, 2a, 3-7 and 5a encode eight known structural proteins, which are minor membrane-associated proteins GP2, E, GP3 and GP4, a major envelope glycoprotein (GP5), a membrane protein (M), a nucleocapsid protein $(\mathrm{N})$ and a novel ORF5a-encoded protein [7-9].

Unlike other arteriviruses, which have a relatively broad cell tropisms [10], PRRSV has a highly restricted tropism for cells of the monocyte-macrophage lineage, specifically porcine alveolar macrophages (PAMs), during acute infection of pigs [11, 12]. Currently, PRRSV can only be propagated in vitro in epithelial-derived MARC-145 cells, a subclone of the African green monkey kidney cell line MA104 [13]. Other cell lines, such as porcine kidney (PK-15), baby hamster kidney cells (BHK-21) and a PAM-derived cell line (CRL-2843) expressing exogenous porcine CD163 (pCD163) are capable of PRRSV infection [14-16]. However, the lack of specialized antibodies recognizing immunologic proteins of porcine origin (e.g., swine cluster of differentiation (CD) antigens and swine leukocyte antigens), has significantly hampered further research on PRRSV pathogenesis mechanisms and virus-triggered immune response cascades in porcine-derived primary cells or cell lines.

To date, host factors involved in the PRRSV cellular tropism are still not fully understood. Numerous in vitro studies have demonstrated that PRRSV infection is determined by various cellular receptors or factors [17] that include heparin sulfate (HS) [18], vimentin [19], CD151 [20], pCD163 [21], sialoadhesin (CD169) [22], DC-SIGN (CD209) [23] and MYH9 [24]. With the development of in vivo genetic engineering technology, recent studies with the gene knocked-out pigs demonstrate that pCD163 [25] but not CD169[26] is indispensable for successful infection with PRRSV.

In this study we introduced pCD163 into a Balb/c J mouse bronchoalveolar macrophage-derived MH-S cell line which undergoes immortalization via introduction of SV40-LT antigen [27], and a mouse macrophage-like
RAW264.7 cell line was derived from a murine leukemia virus (MuLV)-transformed tumor and is free of replication-competent $\mathrm{MuLV}[28,29]$, both of which have been widely used to evaluate macrophage-specific immune responses in vitro [30, 31]. Our results demonstrated that MH-S and RAW264.7 cell lines stably expressed pCD163 (designated MH-S ${ }^{\mathrm{CD} 163}$ and RAW264.7 ${ }^{\mathrm{CD} 163}$, respectively) and supported infection and replication of various genotype 2 PRRSV isolates. Virus titers in MH-S ${ }^{\mathrm{CD} 163}$ cells were similar to that observed in primary PAMs and were even higher than in RAW264.7 ${ }^{\text {CD163 }}$ cells. Moreover, PRRSV-induced cytokine expression patterns in $\mathrm{MH}-\mathrm{S}^{\mathrm{CD} 163}$ cells more closely mirrored patterns observed in PAMs than that observed in RAW264.7 ${ }^{\text {CD163 }}$ cells. Taken together, our findings provide new tools for further research to elucidate PRRSV pathogenesis and cellular immune response mechanisms to PRRSV infection.

\section{Methods \\ Cells and viruses}

A mouse alveolar macrophage-derived cell line $\mathrm{MH}-\mathrm{S}$, a peritoneal macrophage-like cell line RAW264.7 and MARC-145 cells were purchased from the China Center for Type Culture Collection (CCTCC, Wuhan, China). Primary PAMs were prepared from bronchoalveolar lavage of 4 to 6-week-old PRRSV-negative piglets. Culture and preparation of PAMs were conducted as previously described [32, 33]. PAMs and the MH-S cell line were maintained in RPMI 1640 (Gibco, Carlsbad, CA, USA) supplemented with $10 \%$ FBS (v/v; BI, Israel). RAW264.7 and MARC-145 cell lines were cultured in Dulbecco's Modified Eagle Medium (DMEM) (Gibco) containing $10 \%$ fetal bovine serum (FBS) (BI).

Various genotype 2 PRRSV isolates including highly pathogenic PRRSV strains (listed with Genbank accession numbers in parentheses), JXA1 (GenBank: EF112445.1), SD16 (GenBank: JX087437.1), GD-HD (GenBank: KP793736.1) and classical strain VR-2332 (GenBank: AY150564 ) were used to infect the various cell lines at 0.1 to 10 multiplicity of infection (MOI). Viral titers were determined in MARC-145 cells by calculating the median tissue culture infective dose $\left(\mathrm{TCID}_{50}\right)$ as previously described [34].

\section{Transfection vector construction, lentiviral particle preparation and cell transduction}

The cDNA fragment encoding pCD163 (GenBank: JX292263) was amplified from total RNA isolated from PAMs using pCD163-F/pCD163-R primers (Table 1) and ligated into the pTRIP-CMV-Puro lentiviral vector [35] to generate the pTRIP-CMV-Puro-pCD163 construct. Successful insertion of targeting cDNA was verified using DNA sequencing (Sangon Biotech Inc., Shanghai, China). 
Table 1 Primer list for full-length of genome amplification or cytokines expression

\begin{tabular}{|c|c|c|c|}
\hline Genes & Forward primer & Reverse primer & References \\
\hline CD163 & GCTCTAGAATGGTGCTACTTGAAG & CGGGATCCTCATTGTACTTCAGAGTGG & Xiangpeng wang et al. 2013 \\
\hline ORF7 & ATGCCAAATAACAACGGCAAGCAGC & TCATGCTGAGGGTGATGCTGTG & Xiangpeng wang et al. 2013 \\
\hline GAPDH & CCTTCCGTGTCCCTACTGCCAAC & GACGCCTGCTTCACCACCTTCT & Xin-xin Chen et al. 2014 \\
\hline TNFa & $\begin{array}{l}\text { a AACCTCAGATAAGCCCGTCG } \\
\text { b GGCAGGTCTACTITGGAGTCAT }\end{array}$ & $\begin{array}{l}\text { ACCACCAGCTGGTTGTCTIT } \\
\text { CAGAGTAAAGGGGTCAGAGTGG }\end{array}$ & $\begin{array}{l}\text { Gudmundsdottir and Risatti } 2009 \\
\text { Tingyu Wang et al. } 2014\end{array}$ \\
\hline IL4 & $\begin{array}{l}\text { a GCCGGGCCTCGACTGT } \\
\text { b CATCGGCATTTTGAACGAG }\end{array}$ & $\begin{array}{l}\text { TCCGCTCAGGAGGCTCTTC } \\
\text { TGGAAGCCCTACAGACAAGC }\end{array}$ & Dawson et al. 2005 \\
\hline IL10 & $\begin{array}{l}\text { a CGGCGCTGTCATCAATTTCTG } \\
\text { b GGACAACATACTGCTAACCGACT }\end{array}$ & $\begin{array}{l}\text { CCCCTCTCTTGGAGCTTGCTA } \\
\text { TGGGGCATCACTTCTACCA }\end{array}$ & Duvigneau et al. 2005 \\
\hline IFNY & $\begin{array}{l}{ }^{\mathrm{a}} \text { AATGGTAGCTCTGGGAAACTG } \\
\mathrm{b} \text { TGC TGA TGG GAG GAG ATGTCT }\end{array}$ & $\begin{array}{l}\text { ACTTCTCTTCCGCTITCTTAGG } \\
\text { TGC TGT CTG GCC TGC TGT TA }\end{array}$ & $\begin{array}{l}\text { Yoo Jin Lee et al. 2012; Yinhang } \\
\text { Yu et al.2016 }\end{array}$ \\
\hline TGF $\beta$ & $\begin{array}{l}\text { a CGCCTGCTGAGGCAAAGT } \\
\text { b TGACGTCACTGGAGTTGTACGG }\end{array}$ & $\begin{array}{l}\text { GAGGTAGCGCCAGGAATCATT } \\
\text { GGTTCATGTCATGGATGGTGC }\end{array}$ & Min Song et al. 2011 \\
\hline
\end{tabular}

IL interleukin, TNF tumor necrosis factor, TGF transforming growth factor; ${ }^{a}$ primers of swine-origin; ${ }^{\mathrm{b}}$ primers of mouse-origin

Recombinant lentiviral particles carrying pCD163 were obtained by co-transfection of three kinds of vector (pTRIP-CMV-Puro-CD163, pMD2.G and psPAX2) into HEK293T cells using the X-tremeGENE ${ }^{\mathrm{TM}}$ HP DNA Transfection Reagent (Roche, Switzerland) according to the manufacturer's instructions; packed empty lentiviral particles served as the control. Cell culture supernatants containing lentiviral particles were harvested $48 \mathrm{~h}$ posttransfection.

The pCD163-expressing cell lines, $\mathrm{MH}-\mathrm{S}^{\mathrm{CD} 163}$ and RAW264.7 ${ }^{\mathrm{CD} 163}$, were established using transduction of recombinant lentiviruses followed by puromycin selection $(30 \mu \mathrm{g} / \mathrm{ml}$, Merck, USA). Subcloning of surviving cells was done using limiting dilution in 96-well plates. The MH-S and RAW264.7 cells transduced with empty vector were designated $\mathrm{MH}-\mathrm{S}^{\text {vector }}$ and RAW264.7 $7^{\text {vector }}$ and served as control cell lines.

\section{Cell proliferation assay}

Cell proliferation of the various cell lines was assessed as previously described [36, 37] with the following modifications. Briefly, MH-S and RAW264.7 cells transduced with lentiviral particles carrying pCD163 or empty vector, as well as their parental un-transfected cells, were seeded in 24-well plates at a density of $1 \times 10^{4}$ cells/well and were trypsinized daily for a total of eight consecutive days whereby each day half of the cells from each well were removed and counted to determine total cell numbers for evaluation of proliferation rates.

\section{Analysis of PRRSV attachment, internalization, disassembly and infection}

PRRSV attachment, internalization, disassembly and infection of the various cell lines were assayed as previously described [14] with the following modifications. Briefly, MH-S ${ }^{\mathrm{CD} 163}$ and RAW264.7 ${ }^{\mathrm{CD} 163}$ cell lines and
PAMs were incubated with PRRSV strains JXA1 or VR2332 at a MOI of 10. Each cell type was analyzed for each of four stages of virus infection using four replicate cell cultures. For visualization of virus attachment, one replicate cell culture was fixed with $4 \%$ paraformaldehyde after $1 \mathrm{~h}$ of incubation with virus at $4^{\circ} \mathrm{C}$. To observe virus internalization, a second cell replicate culture was incubated at $37^{\circ} \mathrm{C}$ with virus for $1 \mathrm{~h}$ then the cells were fixed and permeabilized for virus visualization. A third cell replicate culture for each treatment was incubated as for the second replicate, but was incubated at $37^{\circ} \mathrm{C}$ for an additional $4 \mathrm{~h}$ and then fixed to measure disassembled viral particles. The fourth replicate cell culture was analyzed by fixation of cells after incubation with virus for $24 \mathrm{~h}$ at $37^{\circ} \mathrm{C}$. For visualization of virus infection at each stage, virus was detected using a mouse monoclonal antibody against PRRSV $\mathrm{N}$ protein (Clone No. 6D10, in house) as previously described [35] and labeled secondary antibody described below.

\section{Western blot}

Sodium dodecyl sulfate-polyacrylamide gel electrophoresis (SDS-PAGE) and western blot were conducted as previously described $[38,39]$ with the following modifications. Briefly, after cells were lysed using NP40 cell lysis buffer (Beyotime, Beijing, China), proteins in each cell lysate were quantified using a Pierce ${ }^{\mathrm{TM}}$ BCA Protein Assay Kit (Thermo Fisher Scientific, Waltham, MA, USA), mixed with 2X Laemmli SDS-PAGE sample buffer then separated using 12\% SDS-PAGE and transferred onto a PVDF membrane (Millipore, Billerica, MA, USA). After blocking with PBS containing 5\% skim milk, the membrane was probed with mouse anti-pCD163 monoclonal antibody (AbD Serotec, Oxford, England) or 6D10. Specific binding of antibodies to their targets was detected by horseradish peroxidase (HRP)-conjugated 
goat anti-mouse IgG (Jackson ImmunoResearch, West Grove, PA, USA) and revealed using ECL chemiluminescence substrates (Bio-Rad, Hercules, CA, USA). The chemiluminescence signal was digitally recorded using a ChemiDoc ${ }^{\mathrm{TM}}$ MP Imaging System (Bio-Rad). The membrane was also probed with mouse anti-GAPDH monoclonal antibody (Sigma-Aldrich, St. Louis, MO, USA) for protein loading normalization.

\section{Immunofluorescence (IFA)}

MH-S ${ }^{\mathrm{CD} 163}$ and RAW264.7 ${ }^{\mathrm{CD} 163}$ cells were seeded onto coverslips and separately infected with various PRRSV strains. Next, cells were fixed with $4 \%$ paraformaldehyde and permeabilized with PBS containing $0.5 \%$ Triton X100 (Sigma-Aldrich). After blocking with PBS containing $1 \%$ BSA, coverslips were probed with mouse antiporcine CD163 monoclonal antibody (AbD Serotec) or 6D10. Specific antibody binding was detected using Alexa Fluor $^{\mathrm{TM}}$ 488-conjugated goat anti-mouse IgG (Thermo Fisher Scientific) and coverslips were mounted onto slides using Prolong Gold antifade reagent containing 4'6-diamidino-2-phenylindole (DAPI) (Thermo Fisher Scientific) for visualization using a Leica AF6000 fluorescence microscope (Leica, Germany).

\section{RNA isolation and quantitative real-time PCR (qPCR)}

Total RNA was isolated from MH-S ${ }^{\mathrm{CD} 163}$ or RAW264.7 ${ }^{\mathrm{CD} 163}$ cell lines or PAMs infected with PRRSV at the indicated time points using RNAiso Plus (TaKaRa, Dalian, China) and reverse transcribed using the PrimeScript $^{\circ} \mathrm{RT}$ reagent Kit (TaKaRa) according to the manufacturer's instructions. The qPCR was performed in duplicates using the StepOne Plus ${ }^{\bullet}$ Real-Time PCR System (Applied Biosystems, Foster City, CA, USA) using FastStart Universal SYBR Green Master (Roche). The equal expression of GAPDH from these cells was confirmed and used to normalize the total amount of input RNA. The related expression levels of indicated genes were quantified by the $2^{-\Delta \Delta C T}$ method as previous described [40]. The qPCR primers and their corresponding sequences are listed in Table 1 and their efficiency was validated.

\section{Statistical analysis}

Statistical significance was assessed using paired twotailed Student's $t$ test with PRISM software (Version 6; GraphPad software). A $P$-value of less than 0.05 was considered to be statistically significant.

\section{Results}

Generation and characterization of $\mathrm{MH}-\mathrm{S}^{\mathrm{CD} 163}$ and RAW264.7 ${ }^{\mathrm{CD} 163}$ cell lines

MH-S ${ }^{\mathrm{CD} 163}$ and RAW264.7 $7^{\mathrm{CD} 163}$ cell lines were generated after transduction of recombinant lentivirus encoding
pCD163 followed by puromycin selection. In both cell lines, the exclusive expression of pCD163 was demonstrated by IFA and western blot; negative expression was observed in controls including parental cells and cells transduced with empty lentiviral vector (Fig. 1a and b). Expression of pCD163 was also supported by the presence of the full-length gene encoding pCD163, as determined by RT-PCR analysis (Fig. 1c).

To evaluate the effect of pCD163 expression on the growth characteristics of MH-S ${ }^{\mathrm{CD} 163}$ and RAW264.7 ${ }^{\mathrm{CD} 163}$ cell lines, growth curves of both cell lines expressing pCD163 were grown in parallel with the parental cells and cells transduced with empty vector. Cells were initially seeded at a density of $1 \times 10^{4}$ cells/well and every $24 \mathrm{~h}$ cultured cell numbers were counted. As shown in Fig. 1d, no differences in cell numbers were observed among pCD163-expressing cells, corresponding parental cells and empty vector-transduced cells.

\section{MH-S ${ }^{\mathrm{CD} 163}$ and RAW264.7 ${ }^{\mathrm{CD} 163}$ cells are susceptible to PRRSV infection} MH-S ${ }^{\mathrm{CD} 163}$, RAW264. $7^{\mathrm{CD} 163}$, parental cells and PAMs were inoculated with the PRRSV JXA1 strain at 1 MOI and PRRSV infection of these cells was determined. As shown in Fig. 2a, a typical cytopathic effect (CPE) was observed in PRRSV-infected MH-S ${ }^{\mathrm{CD} 163}$ and RAW264.7 $7^{\mathrm{CD} 163}$ cells. Moreover, in contrast to undetectable $\mathrm{N}$ protein levels in either MH-S or RAW264.7 cells after incubation with PRRSV for $24 \mathrm{~h}, \mathrm{MH}-\mathrm{S}^{\mathrm{CD} 163}$ and RAW264.7 ${ }^{\mathrm{CD} 163}$ cells and PAMs each demonstrated $\mathrm{N}$ protein detection by IFA (Fig. 2a) and western blot (Fig. 2b).

\section{MH-S ${ }^{\mathrm{CD} 163}$ and RAW264.7 ${ }^{\mathrm{CD} 163}$ cells support replication of various genotype 2 PRRSV isolates}

We next analyzed the PRRSV replication cycle in $\mathrm{MH}-$ $\mathrm{S}^{\mathrm{CD} 163}$ and RAW264.7 ${ }^{\mathrm{CD} 163}$ cells. Both cell lines were inoculated with either JXA1 or VR-2332 at a MOI of 10 and PRRSV-infected PAMs served as the positive control. The PRRSV-N protein was visualized using anti-N protein $\mathrm{mAb}$ to monitor different stages of the PRRSV replication cycle. As shown in Fig. 3a, PRRSV attachment, internalization, disassembly and infection stages were all observed in the MH-S ${ }^{\mathrm{CD} 163}$, RAW264. $7^{\mathrm{CD} 163}$ cells and PAMs. The attachment of virus particles to cell surface was observed first after incubation of cells with virus at $4^{\circ} \mathrm{C}$. Next, virus particles were internalized into cells when the incubation temperature was shifted to $37^{\circ} \mathrm{C}$. As virus particles were disassembled within cells, PRRSVspecific proteins were not clearly detected in infected $\mathrm{MH}$ $\mathrm{S}^{\mathrm{CD} 163}$ and RAW264.7 $7^{\mathrm{CD} 163}$ cells. As assembly of PRRSV virions was eventually completed, PRRSV-N-positive cell staining was again observed in $\mathrm{MH}-\mathrm{S}^{\mathrm{CD} 163}$ and RAW264.7 ${ }^{\mathrm{CD} 163}$ cells at 24 hpi (Fig. 3a). 


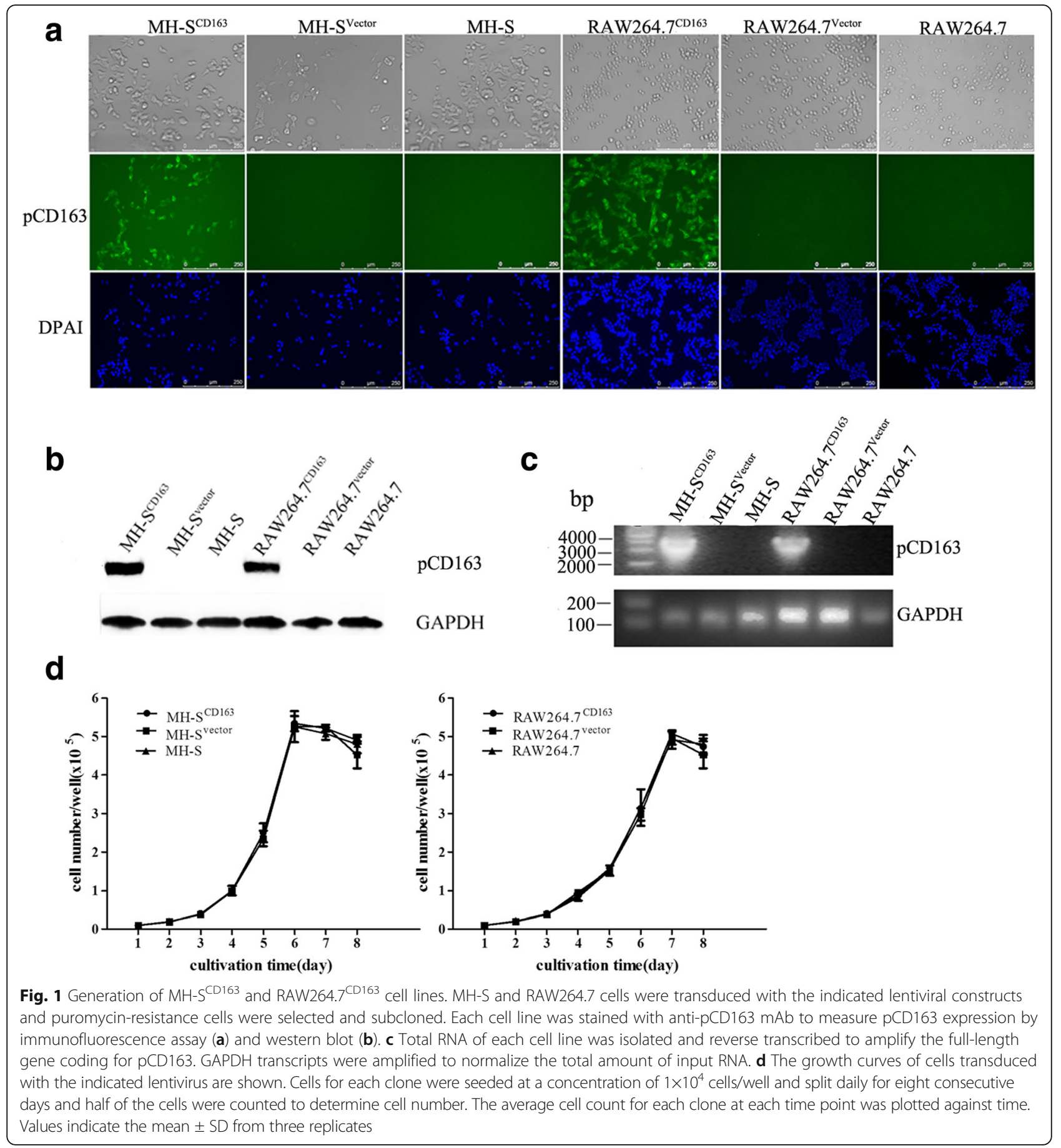

To further evaluate the replication efficiency of PRRSV in $\mathrm{MH}-\mathrm{S}^{\mathrm{CD} 163}$ and RAW264.7 ${ }^{\mathrm{CD} 163}$ cell lines relative to PAMs, the cell lines were separately infected with PRRSV strains VR-2332 and JXA1 at $0.1 \mathrm{MOI}$ and the virus yields at indicated time points were measured by calculating $\mathrm{TCID}_{50}$. As shown in Fig. 3b, no significant difference was observed for either VR-2332 or JXA1 viral titers in MH-S ${ }^{\mathrm{CD} 163}$ cell lines at $12 \mathrm{hpi}$; however, from
24 hpi to 48 hpi significantly lower VR-2332 or JXA1 viral titers were observed in $\mathrm{MH}-\mathrm{S}^{\mathrm{CD} 163}$ cells than in PAMs $(p<0.05)$, with the exception of VR-2332 at 36 hpi. Titers observed in the RAW264. $7^{\mathrm{CD} 163}$ cell line were lowest $(p<0.001)$, while titers at $60 \mathrm{hpi}$ and $72 \mathrm{hpi}$ were significantly higher in $\mathrm{MH}-\mathrm{S}^{\mathrm{CD} 163}$ cells than in PAMs $(p<0.01)$, with the exception of JXA1 at $72 \mathrm{hpi}$. Furthermore, a 12-h lag time to attain peak viral titers 


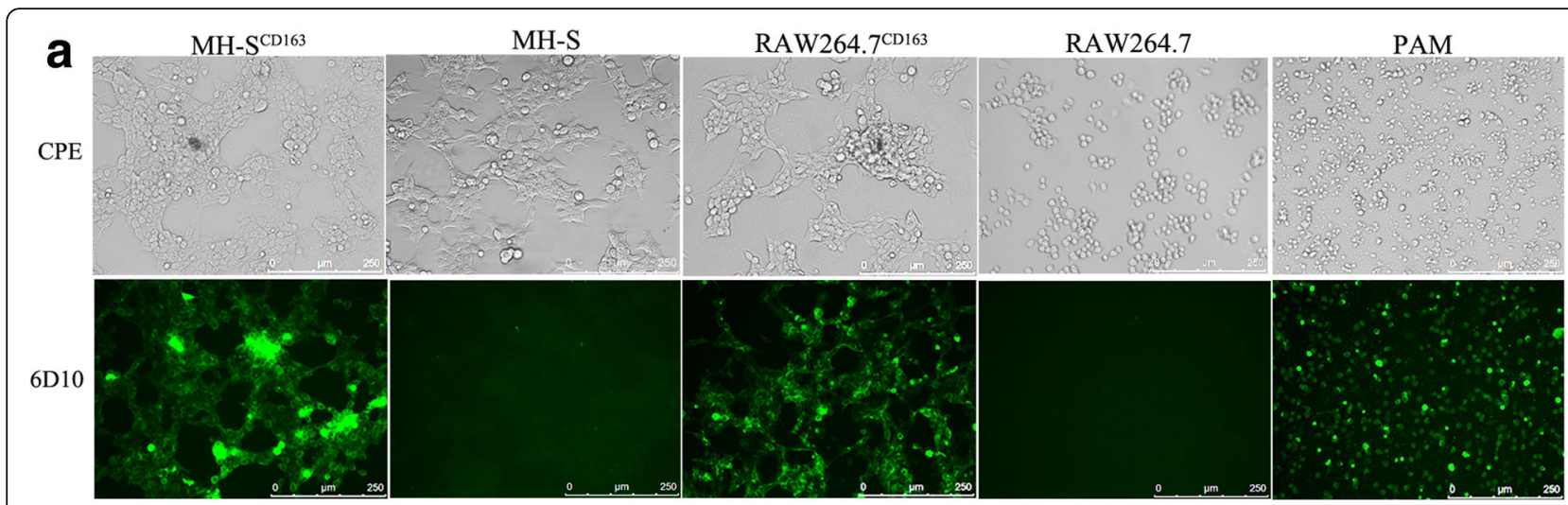

b

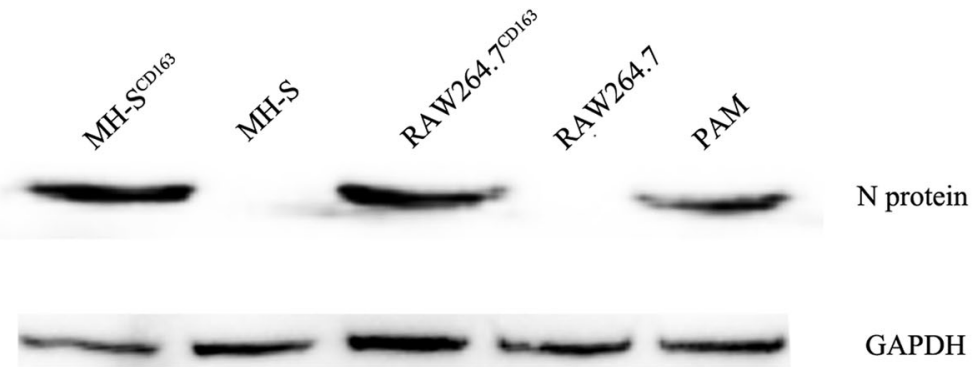

Fig. 2 PRRSV infections in MH-S $S^{\mathrm{CD} 163}$ and RAW264.7 $7^{\mathrm{CD} 163}$ cell lines. The MH-S and RAW264.7 cell lines and PAMs were inoculated with JXA1 at 1 MOI. a CPEs were visualized at 24 hpi using an inverted microscope (200x). Meanwhile, cells were fixed and permeabilized to measure virus infection using immunofluorescence staining of virus using anti-PRRSV N protein-specific mAb (6D10). Images are representative one of three independent experiments. b Cell infection was detected using anti-PRRSV N protein-specific mAb labeling of western blot using GAPDH as the control

was observed for $\mathrm{MH}-\mathrm{S}^{\mathrm{CD} 163}$ cells compared with the time of peak viral titer for PAMs; however, no significant difference in peak titers was observed between $\mathrm{MH}$ $\mathrm{S}^{\mathrm{CD} 163}$ cells at $60 \mathrm{hpi}$ and PAMs at $48 \mathrm{hpi}$.

We further evaluated the replication efficiency of various genotype 2 PRRSV isolates in $\mathrm{MH}-\mathrm{S}^{\mathrm{CD} 163}$ and RAW264.7 ${ }^{\text {CD163 }}$ cells. In agreement with the results in Fig. $3 \mathrm{~b}$, the viral titers of all genotype 2 PRRSV isolates (VR-2332, SD16, JXA1 and GD-HD) in MH-S ${ }^{\mathrm{CD} 163}$ cells were significantly lower than that in PAMs at $48 \mathrm{hpi}(p$ $<0.05)$, while viral titers in RAW264. $7^{\mathrm{CD} 163}$ were the lowest $(p<0.001)$ (Fig. 3c). Collectively, PRRSV replication efficiency in $\mathrm{MH}-\mathrm{S}^{\mathrm{CD} 163}$ cells was more efficient than in RAW264.7 ${ }^{\mathrm{CD} 163}$ cells and was more similar to that observed in PAMs.

\section{Cytokine expression patterns in $\mathrm{MH}-\mathrm{S}^{\mathrm{CD} 163}$ and RAW264.7 ${ }^{\mathrm{CD} 163}$ cell lines after PRRSV infection}

The expression levels of tumor necrosis factor-alpha (TNF- $\alpha$ ), IL-4, IL-10 and interferon- $\gamma$ (IFN- $\gamma$ ) in MH$\mathrm{S}^{\mathrm{CD} 163}$ and RAW264.7 ${ }^{\mathrm{CD} 163}$ cells after PRRSV infection at $24 \mathrm{hpi}$ and $48 \mathrm{hpi}$ were measured and the results are shown in Fig. 4a (JXA1 infection) and Fig. 4b (VR-2332 infection). In JXA1-infected $\mathrm{MH}-\mathrm{S}^{\mathrm{CD} 163}$ cells, a similar pattern of a significant increase of IL-4 and IL-10 mRNA expression at $24 \mathrm{hpi}$ followed by a decrease at $48 \mathrm{hpi}$ was observed and mirrored the expression pattern in PAMs $(p<0.01)$. Meanwhile, TNF- $\alpha$ mRNA level decreased at $24 \mathrm{hpi}$ and increased at $48 \mathrm{hpi}$ in JXA1infected $\mathrm{MH}-\mathrm{S}^{\mathrm{CD} 163}$ cells. IFN- $\gamma$ mRNA in both JXA1-infected MH-S ${ }^{\mathrm{CD} 163}$ cells and PAMs exhibited for a low basal level of expression. In JXA1-infected RAW264.7 ${ }^{\mathrm{CD} 163}$ cells, the highest mRNA expression of IL- 4 and IFN- $\gamma$ at 24 hpi and TNF- $\alpha$ and IL-10 at 48 hpi were observed (Fig. 4a). In Fig. 4b, the mRNA expression level of TNF- $\alpha$ in $\mathrm{MH}-\mathrm{S}^{\mathrm{CD} 163}$ cells was similar to that for PAMs after VR-2332 infection. A significant up-regulation of mRNA expression levels of IL-4 and IL-10 was observed in $\mathrm{MH}-\mathrm{S}^{\mathrm{CD} 163}$ and RAW264. $7^{\text {CD163 }}$ cells at 24 hpi $(p<0.001)$ relative to mock infected controls, which mirrored the pattern observed in PAMs. Moreover, a significant increase of IFN- $\gamma$ mRNA was detected in $\mathrm{MH}-\mathrm{S}^{\mathrm{CD} 163}$ at $48 \mathrm{hpi}$ and RAW264. $7^{\text {CD163 }}$ cells at 24 hpi $(p<0.01)$. Taken together, the characteristics of cytokine expression in $\mathrm{MH}-\mathrm{S}^{\mathrm{CD} 163}$ cells were more similar to expression patterns in PAMs as compared to patterns observed in RAW264.7 ${ }^{\text {CD163 }}$ cells.

\section{Discussion}

In vitro, efficient PRRSV replication can only be observed in porcine-derived primary cells (e.g., PAMs) and 


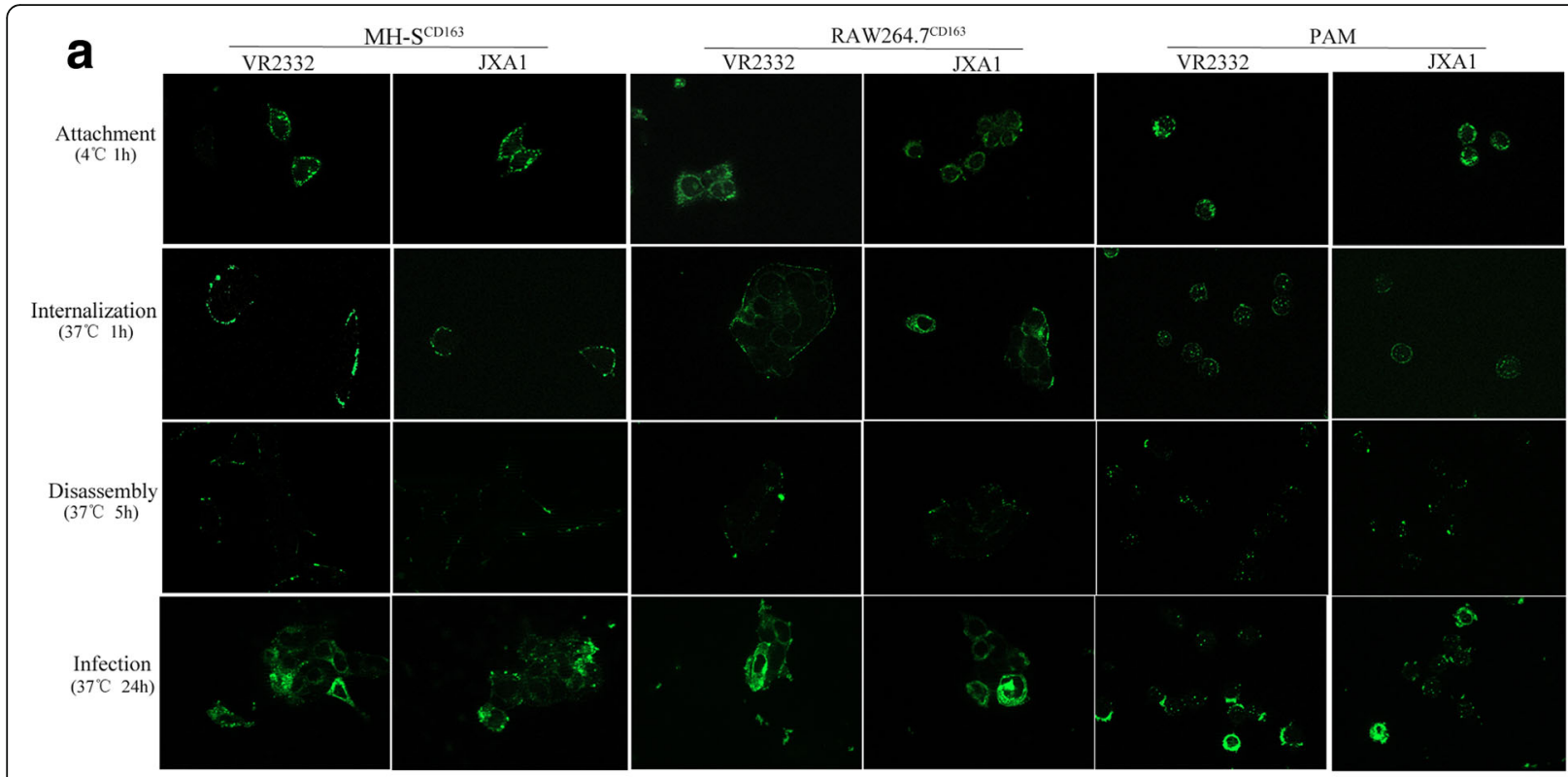

b

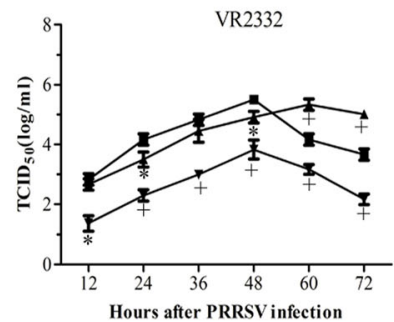

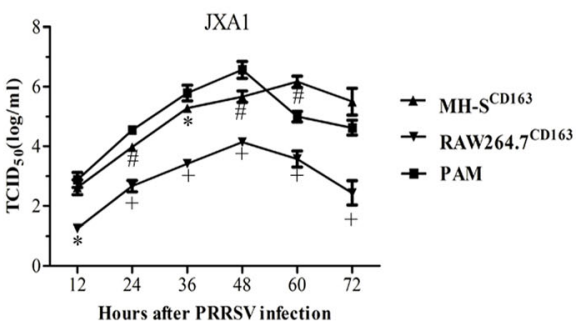

C

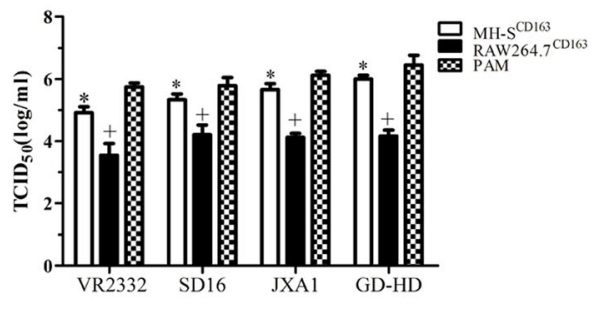

Fig. 3 Susceptibility of MH-S $S^{\mathrm{CD} 163}$ and RAW264.7 $7^{\mathrm{CD} 163}$ cell lines to various genotype 2 PRRSV isolates. a MH-S ${ }^{\mathrm{CD} 163}$ and RAW264.7 $7^{\mathrm{CD} 163}$ cell lines and PAMs were inoculated with JXA1 and VR-2332 at $10 \mathrm{MOI}$. Various sequential stages of the viral replication cycle were measured by immunofluorescence staining of virus using anti-PRRSV N protein-specific mAb. Images are representative of three independent experiments. $\mathbf{b}$ PRRSV replication in MH$S^{\mathrm{CD} 163}$ and RAW264.7 ${ }^{\mathrm{CD} 163}$ cells. The MH-S ${ }^{\mathrm{CD} 163}$ cells (triangle), RAW264.7 ${ }^{\mathrm{CD} 163}$ cells (inverted triangle) and PAMs (square) were inoculated with JXA1 and VR-2332 at $0.1 \mathrm{MOI}$. The lysate of each infected cell line at the indicated time points was collected and titrated on MARC-145. Values represent the mean \pm SD from three independent experiments. ${ }^{*}, P<0.05{ }^{*}, P<0.01 ;{ }^{+}, P<0.001$. c The MH-S ${ }^{C D 163}$ and RAW264. ${ }^{\mathrm{CD} 163}$ cells, parental cell lines and PAMs were inoculated with various PRRSV isolates (VR-2332, SD16, JXA1 and GD-HD) at 0.1 MOI. The lysate of each cell line infected with each indicated PRRSV isolate was collected at 48 hpi and titrated on MARC-145 cells. Values indicate the mean \pm SD from three independent experiments. ${ }^{*}, P<0.05$; ${ }^{,}, P<$ $0.01 ;{ }^{+}, P<0.001$

MARC-145 cells. Moreover, PK-15, BHK-21 and CRL2843 cell lines expressing pCD163 were also used in some cases for PRRSV infection. However, due to the lack of designation of novel porcine origin immunologic molecules as human or mouse counterpart and corresponding antibodies, studies on PRRSV pathogenesis and immune responses in swine-derived primary cells or cells lines have been significantly hampered. Considering that these two murine cell lines used in this study were derived from murine macrophage lineage which classically designated to be involved in innate and/or adaptive immune responses, it would be critical to investigate whether they may further mimic the natural host PAMs for PRRSV infection in vitro. Therefore, we developed
MH-S ${ }^{\mathrm{CD} 163}$ and RAW264.7 ${ }^{\mathrm{CD} 163}$ cell lines stably expressing pCD163 that support PRRSV infection with similar features as that observed in PAMs.

CD163 is a group B cysteine-rich scavenger receptor expressed exclusively in cells of the monocyte-macrophage lineage [41]. As a type I membrane protein, the extracellular region of CD163 contains nine scavenger receptor cysteine-rich (SRCR) domains (SRCR1-9) and is anchored by a single transmembrane portion and a short cytoplasmic domain [42, 43]. Biologically, membrane-associated CD163 is responsible for mediating endocytosis of hemoglobin-haptoglobin complexes to prevent tissue damage caused by free hemoglobin-catalyzed production of iron-derived hydroxyl radicals [44-46] and modulating 


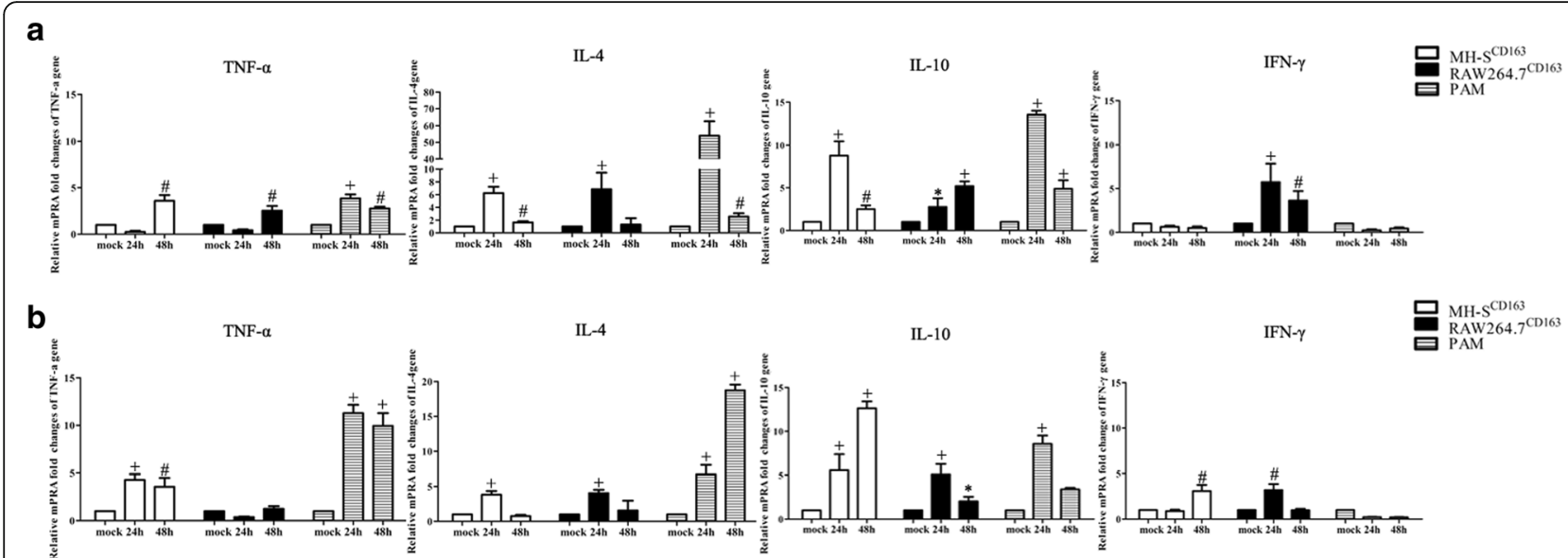

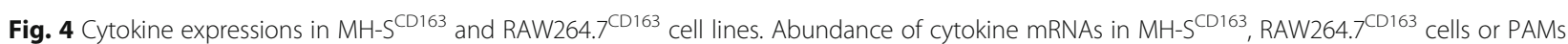
inoculated with JXA1 (a) and VR-2332 (b) was determined by qPCR. Values were normalized to corresponding uninfected MH-S ${ }^{\mathrm{CD} 163}$, RAW264.7 $7^{\mathrm{CD} 163}$ cells or PAMs at $24 \mathrm{hpi}$, respectively, and indicate the mean \pm SD from three replicates. ${ }^{*}, P<0.05 ;^{\#}, P<0.01 ;^{+}, P<0.001$

systemic immune homeostasis, particularly with respect to anti-inflammation [47]. In in vivo study, alveolar macrophages from asthmatic patients with reduced cell-surface expression of CD163 associated with inflammatory effects, which was similar as that observed in CD163 knock-out mice [47]. CD163 also serves as a receptor for erythroblasts, bacteria and viruses [48-50]. Increasing evidence has demonstrated that pCD163 is identified as a fusion receptor for PRRSV[25, 43], a further study on generation of genome edited pigs with the deletion of SRCR5 confirmed SRCR5 of pCD163 was essential for successful infection with PRRSV, more importantly, there was no other biological function of pCD163 affected[51]. Pro-inflammatory and anti-inflammatory effects caused by virus infection were demonstrated to associate with CD163 expressed on immune cells [52]. However, regarding pCD163, whether or not it plays the same role as its human counterpart remains to be elucidated; as yet we may not rule out the possibility of other SRCR domains involved in its other biological functions.

From the study of van Breedam's group, non-permissive BHK21 cells were found to be rendered susceptible to PRRSV infection with transfection of CD163 cDNAs from various species (e.g., human-, monkey-, murine- and porcine-origin), [53]. While these observations partially explain the susceptibility of CD163-transfected Marc145 cells to PRRSV in vitro, they do not explain why swine and related species of wild boar are the only known in vivo hosts of PRRSV. Moreover, although truncation assays have demonstrated that SRCR5 of pCD163 mediates PRRSV infection [54], replacement of the SRCR5 domain of pCD163 with the SRCR5 domain from the human CD163-like homolog (CD163Li) only conferred resistance to genotype 1 PRRSV, not genotype 2 virus [55]. Therefore, mechanisms of CD163 involvement in PRRSV infection are still not fully understood and the roles played by CD163 from various species in PRRSV infection remain to be elucidated. Since knockout of pCD163 confers complete resistance to PRRSV in swine, it would be interesting to know whether replacement of murine CD163 with porcine CD163 could render mice susceptible to PRRSV.

Based on our data, expression of endogenous murine CD163 in both parental cell lines was undetectable at the protein level (Additional file 1: Figure S1), which is consistent with findings of a previous study showing expression of murine CD163 at a low basal level in RAW264.7 cells using qPCR [56]. Moreover, analyses of PRRSV replication and PRRSV-N protein expression have indicated that parental MH-S and RAW264.7 cells are not susceptible to PRRSV infection.

According to our results, $\mathrm{MH}-\mathrm{S}^{\mathrm{CD} 163}$ cells may be more susceptible to PRRSV infection due to significantly higher virus titers in $\mathrm{MH}-\mathrm{S}^{\mathrm{CD} 163}$ cells compared with that observed in RAW264.7 ${ }^{\text {CD163 }}$ cells. Furthermore, we found significantly lower viral titers of all genotype 2 PRRSV isolates were in $\mathrm{MH}-\mathrm{S}^{\mathrm{CD} 163}$ cells at 48 hpi compared with titers in PAMs (Fig. 3c), probably due to a 12-h lag time to reach peak viral titers in $\mathrm{MH}-\mathrm{S}^{\mathrm{CD} 163}$ cells in comparison to PAMs (Fig. 3b).

The poor adaptive immune response to PRRSV in piglets has been partially ascribed to abnormal upregulation of IL-10 [57]. Moreover, PRRSV-induced IL-10 production has been reported to be associated with low levels of IFN- $\gamma$ production in infected cells $[58,59]$. In our study, up-regulation of IL-10 and down-regulation of IFN$\gamma$ were observed in PRRSV-infected $\mathrm{MH}-\mathrm{S}^{\mathrm{CD} 163}$ cells, which is consistent with data regarding cytokine production by PAMs. 


\section{Conclusion}

Two PRRSV-susceptible murine macrophage-derived cell lines were established by introducing pCD163 in $\mathrm{MH}-\mathrm{S}$ and RAW264.7 cells. Consequently, the $\mathrm{MH}$ $S^{\text {CD163 }}$ cell line was shown to have greater investigational value for further study of immune responses after PRRSV infection, since its PRRSV susceptibility and mRNA cytokine expression levels were relatively similar to those observed for primary PAMs. Our research thus provides mouse macrophage cell models which may mimic natural host cells in vitro to aid the study of PRRSV pathogenesis and immune response mechanisms to viral infection.

\section{Additional file}

Additional file 1: Figure S1. Endogenous mCD163 expression in $\mathrm{MH}-\mathrm{S}$ and RAW264.7 cell lines. MH-S and RAW264.7 cell lysates were separated by SDS-PAGE and proteins were transferred to PVDV membrane and probed with anti-pig CD163 SRCR1-4 polyclonal antisssbody that cross reacts with $\mathrm{mCD} 163$. Mouse liver tissue lysate served as the positive control by western blot using GAPDH as the internal protein control. (JPEG 8 kb)

\section{Abbreviations}

BHK-21: baby hamster kidney cells; CD: cluster of differentiation; CPE: cytopathic effect; DAPI: 4'6-diamidino-2-phenylindole; DMEM: Dulbecco's Modified Eagle Medium; FBS: fetal bovine serum; HRP: horseradish peroxidase; HS: heparin sulfate; IFA: Immunofluorescence assay; IFN- $\gamma$ : interferon- $\gamma$; MOI: multiplicity of infection; MuLV: murine leukemia virus; ORFs: open reading frames; PAMs: porcine alveolar macrophages; pCD163: porcine CD163; pi: postinfection; PK-15: porcine kidney cell line; PRRSV: porcine reproductive and respiratory syndrome virus; qPCR: quantitative real-time PCR; SDS-PAGE: Sodium dodecyl sulfate-polyacrylamide gel electrophoresis; SRCR: scavenger receptor cysteine-rich; $\mathrm{TCID}_{50}$ : the median tissue culture infective dose; TNF-a: tumor necrosis factor-alpha

\section{Acknowledgements}

We thank Dr. Enqi Du (Northwest A\&F University) for providing the recombinant lentiviral system.

\section{Funding}

We acknowledge financial support of the National Key R\&D Program of China (2016YFD0500706) and National Natural Science Foundation of China (31430084).

\section{Availability of data and materials}

The datasets used and analyzed during the current study are available from the corresponding author on reasonable request.

\section{Authors' contributions}

EMZ conceived and designed the study. CW, EMZ and LL wrote the paper. $\mathrm{LL}, \mathrm{GH}, \mathrm{BX}$ and XS performed the experiments. GZ, QZ, YN and EMZ revised the manuscript. All of the authors reviewed the results and approved the final version of the manuscript.

Ethics approval and consent to participate

Not applicable.

\section{Consent to publication}

Not applicable.

\section{Competing interests}

The authors declare that they have no competing interests.

\section{Publisher's Note}

Springer Nature remains neutral with regard to jurisdictional claims in published maps and institutional affiliations.

\section{Author details}

${ }^{1}$ Department of Preventive Veterinary Medicine, College of Veterinary Medicine, Northwest A\&F University, Yangling, Shaanxi, China. ${ }^{2}$ Scientific Observing and Experimental Station of Veterinary Pharmacology and Diagnostic Technology, Ministry of Agriculture, Yangling, Shaanxi, China. ${ }^{3}$ College of Animal Science and Veterinary Medicine, Henan Agricultural University, Zhengzhou, Henan, China.

Received: 27 May 2017 Accepted: 31 October 2017 Published online: 09 November 2017

\section{References}

1. Rowland RR, Lunney J, Dekkers J. Control of porcine reproductive and respiratory syndrome (PRRS) through genetic improvements in disease resistance and tolerance. Frontiers in genetics. 2012;3:260.

2. Dokland T. The structural biology of PRRSV. Virus research. 2010;154(1-2):86-97.

3. Snijder EJ, Meulenberg JJ. The molecular biology of arteriviruses. The Journal of general virology. 1998;79(Pt 5):961-79.

4. Meng XJ, Paul PS, Halbur PG, Lum MA. Phylogenetic analyses of the putative $M$ (ORF 6) and N (ORF 7) genes of porcine reproductive and respiratory syndrome virus (PRRSV): implication for the existence of two genotypes of PRRSV in the U.S.A. and Europe. Archives of virology. 1995; 140(4):745-55.

5. Nelsen CJ, Murtaugh MP, Faaberg KS. Porcine reproductive and respiratory syndrome virus comparison: divergent evolution on two continents. Journal of virology. 1999;73(1):270-80.

6. Lunney JK, Fang Y, Ladinig A, Chen N, Li Y, Rowland B, Renukaradhya GJ. Porcine Reproductive and Respiratory Syndrome Virus (PRRSV): Pathogenesis and Interaction with the Immune System. Annual review of animal biosciences. 2016:4:129-54.

7. Mardassi H, Mounir S, Dea S. Molecular analysis of the ORFs 3 to 7 of porcine reproductive and respiratory syndrome virus, Quebec reference strain. Arch Virol. 1995;140(8):1405-18.

8. Meulenberg JJ, Petersen-Den Besten A, De Kluyver EP, Moormann RJ, Schaaper WMM, Wensvoort G. Characterization of proteins encoded by ORFs 2 to 7 of Lelystad virus. Virology. 1995;206:155-63.

9. Johnson CR, Griggs TF, Gnanandarajah J, Murtaugh MP. Novel structural protein in porcine reproductive and respiratory syndrome virus encoded by an alternative ORF5 present in all arteriviruses. The Journal of general virology. 2011;92(Pt 5):1107-16.

10. Zhang Q, Yoo D. PRRS virus receptors and their role for pathogenesis. Vet Microbiol. 2015;177(3-4):229-41.

11. Morgan SB, Frossard JP, Pallares FJ, Gough J, Stadejek T, Graham SP, Steinbach F, Drew TW, Salguero FJ. Pathology and Virus Distribution in the Lung and Lymphoid Tissues of Pigs Experimentally Inoculated with Three Distinct Type 1 PRRS Virus Isolates of Varying Pathogenicity. Transboundary and emerging diseases. 2014;

12. Rossow KD, Collins JE, Goyal SM, Nelson EA, Christopher Hennings J, Benfield DA. Pathogenesis of porcine reproductive and respiratory syndrome virus infection in gnotobiotic pigs. Vet Pathol. 1995;32(4):361-73.

13. Kim HS, Kwang J, Yoon IJ, Joo HS, Frey ML. Enhanced replication of porcine reproductive and respiratory syndrome (PRRS) virus in a homogeneous subpopulation of MA-104 cell line. Arch Virol. 1993;133(3-4):477-83.

14. Delrue I, Van Gorp H, Van Doorsselaere J, Delputte PL, Nauwynck HJ. Susceptible cell lines for the production of porcine reproductive and respiratory syndrome virus by stable transfection of sialoadhesin and CD163. BMC biotechnology. 2010;10:48.

15. Wang X, Wei R, Li Q, Liu H, Huang B, Gao J, Mu Y, Wang C, Hsu WH, Hiscox JA, et al. PK-15 cells transfected with porcine CD163 by PiggyBac transposon system are susceptible to porcine reproductive and respiratory syndrome virus. J Virol Methods. 2013;193(2):383-90.

16. Calvert JG, Slade DE, Shields SL, Jolie R, Mannan RM, Ankenbauer RG, Welch SK. CD163 expression confers susceptibility to porcine reproductive and respiratory syndrome viruses. Journal of virology. 2007;81(14):7371-9.

17. Shi C, Liu Y, Ding Y, Zhang Y, Zhang J. PRRSV receptors and their roles in virus infection. Archives of microbiology. 2015;197(4):503-12. 
18. Delputte PL, Vanderheijden N, Nauwynck HJ, Pensaert MB. Involvement of the matrix protein in attachment of porcine reproductive and respiratory syndrome virus to a heparinlike receptor on porcine alveolar macrophages. J Virol. 2002;76(9):4312-20.

19. Kim JK, Fahad AM, Shanmukhappa K, Kapil S. Defining the cellular target(s) of porcine reproductive and respiratory syndrome virus blocking monoclonal antibody 7G10. Journal of virology. 2006:80(2):689-96.

20. Wu J, Peng X, Zhou A, Qiao M, Wu H, Xiao H, Liu G, Zheng X, Zhang S, Mei S. MiR-506 inhibits PRRSV replication in MARC-145 cells via CD151. Molecular and cellular biochemistry. 2014;394(1-2):275-81.

21. Guo L, Niu J, Yu H, Gu W, Li R, Luo X, Huang M, Tian Z, Feng L, Wang Y. Modulation of CD163 expression by metalloprotease ADAM17 regulates porcine reproductive and respiratory syndrome virus entry. J Virol. 2014; 88(18):10448-58.

22. Delputte PL, Van Breedam W, Delrue I, Oetke C, Crocker PR, Nauwynck HJ. Porcine arterivirus attachment to the macrophage-specific receptor sialoadhesin is dependent on the sialic acid-binding activity of the $\mathrm{N}$ terminal immunoglobulin domain of sialoadhesin. Journal of virology. 2007; 81(17):9546-50.

23. Pineyro PE, Subramaniam S, Kenney SP, Heffron CL, Gimenez-Lirola LG, Meng XJ. Modulation of Proinflammatory Cytokines in Monocyte-Derived Dendritic Cells by Porcine Reproductive and Respiratory Syndrome Virus Through Interaction with the Porcine Intercellular-Adhesion-Molecule-3Grabbing Nonintegrin. Viral immunology. 2016;29(10):546-56.

24. Gao J, Xiao S, Xiao Y, Wang X, Zhang C, Zhao Q, Nan Y, Huang B, Liu H, Liu $\mathrm{N}$, et al. MYH9 is an Essential Factor for Porcine Reproductive and Respiratory Syndrome Virus Infection. Scientific reports. 2016;6:25120.

25. Whitworth KM, Rowland RR, Ewen CL, Trible BR, Kerrigan MA, Cino-Ozuna AG, Samuel MS, Lightner JE, McLaren DG, Mileham AJ, et al. Gene-edited pigs are protected from porcine reproductive and respiratory syndrome virus. Nature biotechnology. 2016;34(1):20-2.

26. Prather RS, Rowland RR, Ewen C, Trible B, Kerrigan M, Bawa B, Teson JM, Mao J, Lee K, Samuel MS, et al. An intact sialoadhesin (Sn/SIGLEC1/ CD169) is not required for attachment/internalization of the porcine reproductive and respiratory syndrome virus. Journal of virology. 2013; 87(17):9538-46.

27. Mbawuike IN, Herscowitz HB. MH-S, a murine alveolar macrophage cell line: morphological, cytochemical, and functional characteristics. Journal of leukocyte biology. 1989;46(2):119-27.

28. Raschke WC, Baird S, Ralph P, Nakoinz I. Functional macrophage cell lines transformed by Abelson leukemia virus. Cell. 1978;15(1):261-7.

29. Hartley JW, Evans LH, Green KY, Naghashfar Z, Macias AR, Zerfas PM, Ward JM. Expression of infectious murine leukemia viruses by RAW264.7 cells, a potential complication for studies with a widely used mouse macrophage cell line. Retrovirology. 2008;5:1.

30. Gan ZS, Wang QQ, Li JH, Wang XL, Wang YZ, Du HH. Iron Reduces M Macrophage Polarization in RAW264.7 Macrophages Associated with Inhibition of STAT1. Mediators of inflammation. 2017:8570818:2017.

31. Damte D, Lee SJ, Birhanu BT, Suh JW, Park SC. Sonicated Protein Fractions of Mycoplasma hyopneumoniae Induce Inflammatory Responses and Differential Gene Expression in a Murine Alveolar Macrophage Cell Line. Journal of microbiology and biotechnology. 2015;25(12):2153-9.

32. Patel D, Opriessnig T, Stein DA, Halbur PG, Meng XJ, Iversen PL, Zhang YJ. Peptide-conjugated morpholino oligomers inhibit porcine reproductive and respiratory syndrome virus replication. Antiviral Res. 2008;77(2):95-107.

33. Xiao S, Zhang A, Zhang C, Ni H, Gao J, Wang C, Zhao Q, Wang X, Ma C, Liu $H$, et al. Heme oxygenase- 1 acts as an antiviral factor for porcine reproductive and respiratory syndrome virus infection and over-expression inhibits virus replication in vitro. Antiviral research. 2014;110:60-9.

34. Du Y, Du T, Shi Y, Zhang A, Zhang C, Diao Y, Jin G, Zhou EM. Synthetic Tolllike receptor 7 ligand inhibits porcine reproductive and respiratory syndrome virus infection in primary porcine alveolar macrophages. Antiviral Res. 2016;131:9-18.

35. Li Q, Wang X, Wang C, Yu Y, Wang G, Gao J, Liu H, Xie H, Huang B, Li $Z$, et al. Intracellular expression of an anti-idiotypic antibody singlechain variable fragment reduces porcine reproductive and respiratory syndrome virus infection in MARC-145 cells. Antiviral therapy. 2016;21(2): 161-70.

36. Liu H, Wang Y, Duan H, Zhang A, Liang C, Gao J, Zhang C, Huang B, Li Q, Li $\mathrm{N}$, et al. An intracellularly expressed Nsp9-specific nanobody in MARC-145 cells inhibits porcine reproductive and respiratory syndrome virus replication. Veterinary microbiology. 2015;181(3-4):252-60.

37. Mu Y, Li L, Zhang B, Huang B, Gao J, Wang X, Wang C, Xiao S, Zhao Q, Sun $Y$, et al. Glycoprotein 5 of porcine reproductive and respiratory syndrome virus strain SD16 inhibits viral replication and causes G2/M cell cycle arrest, but does not induce cellular apoptosis in Marc-145 cells. Virology. 2015;484: 136-45.

38. Patel D, Nan Y, Shen M, Ritthipichai K, Zhu X, Zhang YJ. Porcine reproductive and respiratory syndrome virus inhibits type I interferon signaling by blocking STAT1/STAT2 nuclear translocation. J Virol. 2010; 84(21):11045-55.

39. Nan Y, Wang R, Shen M, Faaberg KS, Samal SK, Zhang YJ. Induction of type interferons by a novel porcine reproductive and respiratory syndrome virus isolate. Virology. 2012;432(2):261-70.

40. Livak KJ, Schmittgen TD: Analysis of relative gene expression data using real-time quantitative PCR and the 2(-Delta Delta C(T)) Method. Methods (San Diego, CA) 2001, 25(4):402-408.

41. Law SK, Micklem KJ, Shaw JM, Zhang XP, Dong Y, Willis AC, Mason DY. A new macrophage differentiation antigen which is a member of the scavenger receptor superfamily. European journal of immunology. 1993; 23(9):2320-5.

42. Van Gorp H, Delputte PL, Nauwynck HJ. Scavenger receptor CD163, a Jackof-all-trades and potential target for cell-directed therapy. Mol Immunol. 2010;47(7-8):1650-60.

43. Ma H, Jiang L, Qiao S, Zhi Y, Chen XX, Yang Y, Huang X, Huang M, Li R, Zhang GP. The Crystal Structure of the Fifth Scavenger Receptor CysteineRich Domain of Porcine CD163 Reveals an Important Residue Involved in Porcine Reproductive and Respiratory Syndrome Virus Infection. J Virol. 2017;91(3)

44. Sadrzadeh SM, Graf E, Panter SS, Hallaway PE, Eaton JW. Hemoglobin. A biologic fenton reagent. J Biol Chem. 1984;259(23):14354-6.

45. Lim SK, Kim H. bin Ali A, Lim YK, Wang Y, Chong SM, Costantini F, Baumman $\mathrm{H}$ : Increased susceptibility in $\mathrm{Hp}$ knockout mice during acute hemolysis. Blood. 1998;92(6):1870-7.

46. Kristiansen M, Graversen JH, Jacobsen C, Sonne O, Hoffman HJ, Law SK, Moestrup SK. Identification of the haemoglobin scavenger receptor. Nature. 2001;409(6817):198-201.

47. Dai C, Yao X, Gordon EM, Barochia A, Cuento RA, Kaler M, Meyer KS, Keeran KJ, Nugent GZ, Jeffries KR, et al. A CCL24-dependent pathway augments eosinophilic airway inflammation in house dust mite-challenged Cd163(-/-) mice. Mucosal immunology. 2016;9(3):702-17.

48. Fabriek $\mathrm{BO}$, Polfliet MM, Vloet RP, van der Schors RC, Ligtenberg AJ, Weaver LK, Geest C, Matsuno K, Moestrup SK, Dijkstra CD, et al. The macrophage CD163 surface glycoprotein is an erythroblast adhesion receptor. Blood. 2007;109(12):5223-9.

49. Fabriek BO, van Bruggen R, Deng DM, Ligtenberg AJ, Nazmi K, Schornagel $K$, Vloet RP, Dijkstra CD, van den Berg TK. The macrophage scavenger receptor CD163 functions as an innate immune sensor for bacteria. Blood. 2009;113(4):887-92.

50. Cai Y, Postnikova EN, Bernbaum JG, SQ Y, Mazur S, Deiuliis NM, Radoshitzky SR, Lackemeyer MG, McCluskey A, Robinson PJ, et al. Simian hemorrhagic fever virus cell entry is dependent on CD163 and uses a clathrin-mediated endocytosis-like pathway. Journal of virology. 2015;89(1):844-56.

51. Burkard C, Lillico SG, Reid E, Jackson B, Mileham AJ, Ait-Ali T, Whitelaw CB, Archibald AL. Precision engineering for PRRSV resistance in pigs: Macrophages from genome edited pigs lacking CD163 SRCR5 domain are fully resistant to both PRRSV genotypes while maintaining biological function. PLoS pathogens. 2017;13(2):e1006206.

52. Nowlin BT, Burdo TH, Midkiff CC, Salemi M, Alvarez X, Williams KC. SIV encephalitis lesions are composed of CD163(+) macrophages present in the central nervous system during early SIV infection and SIV-positive macrophages recruited terminally with AIDS. The American journal of pathology. 2015;185(6):1649-65.

53. Van Breedam W, Delputte PL, Van Gorp H, Misinzo G, Vanderheijden N, Duan $X$, Nauwynck HJ. Porcine reproductive and respiratory syndrome virus entry into the porcine macrophage. The Journal of general virology. 2010; 91(Pt 7):1659-67.

54. Van Gorp H, Van Breedam W, Van Doorsselaere J, Delputte PL, Nauwynck $\mathrm{HJ}$. Identification of the CD163 protein domains involved in infection of the porcine reproductive and respiratory syndrome virus. J Virol. 2010;84(6): 3101-5. 
55. Wells KD, Bardot R, Whitworth KM, Trible BR, Fang Y, Mileham A, Kerrigan MA, Samuel MS, Prather RS, Rowland RR. Replacement of Porcine CD163 Scavenger Receptor Cysteine-Rich Domain 5 with a CD163-Like Homolog Confers Resistance of Pigs to Genotype 1 but Not Genotype 2 Porcine Reproductive and Respiratory Syndrome Virus. J Virol. 2017;91(2)

56. Zhang Z, Zhang ZY, Schittenhelm J, Wu Y, Meyermann R, Schluesener HJ. Parenchymal accumulation of CD163+ macrophages/microglia in multiple sclerosis brains. Journal of neuroimmunology. 2011;237(1-2):73-9.

57. Johnsen CK, Botner A, Kamstrup S, Lind P, Nielsen J. Cytokine mRNA profiles in bronchoalveolar cells of piglets experimentally infected in utero with porcine reproductive and respiratory syndrome virus: association of sustained expression of IFN-gamma and IL-10 after viral clearance. Viral immunology. 2002;15(4):549-56.

58. Royaee AR, Husmann RJ, Dawson HD, Calzada-Nova G, Schnitzlein WM, Zuckermann FA, Lunney JK. Deciphering the involvement of innate immune factors in the development of the host response to PRRSV vaccination. Veterinary immunology and immunopathology. 2004;102(3):199-216.

59. Suradhat $\mathrm{S}$, Thanawongnuwech $\mathrm{R}$. Upregulation of interleukin-10 gene expression in the leukocytes of pigs infected with porcine reproductive and respiratory syndrome virus. The Journal of general virology. 2003;84(Pt 10): 2755-60.

\section{Submit your next manuscript to BioMed Central and we will help you at every step:}

- We accept pre-submission inquiries

- Our selector tool helps you to find the most relevant journal

- We provide round the clock customer support

- Convenient online submission

- Thorough peer review

- Inclusion in PubMed and all major indexing services

- Maximum visibility for your research

Submit your manuscript at www.biomedcentral.com/submit 